\title{
LXXXIX. On the application of alternating currents to the calibration of capacity-boxes, and to the comparison of capacities and inductances
}

\author{
W. Stroud M.A. D.Sc. \& J. H. Oates B.Sc.
}

To cite this article: W. Stroud M.A. D.Sc. \& J. H. Oates B.Sc. (1903) LXXXIX. On the application of alternating currents to the calibration of capacity-boxes, and to the comparison of capacities and inductances, Philosophical Magazine Series 6, 6:36, 707-720, DOI: $10.1080 / 14786440309463075$

To link to this article: http://dx.doi.org/10.1080/14786440309463075

Published online: 15 Apr 2009.

Submit your article to this journal

Џ Article views: 2

View related articles $\sqsubset$

Citing articles: 1 View citing articles ¿ð 
was made tight by a mercury seal. The tube, with the radium beside it, was placed in a large box lined with lead.

In making the experiments the tube was sealed to a threefall Sprengel pump and exhausted, being gently warmed at intervals during the process. When the McLeod gauge showed a high vacuum had been obtained dry air was slowly admitted through a series of drying-tubes until atmospheric pressure was reached. The glass tube giving connexion with the external air was then sealed off and observations of the potential-difference were commenced. The pump was started and kept working for about six hours, readings of the electrometer being taken from time to time. When the highest vacuum attainable had been reached dry air was once more admitted to the testing-vessel, but no alteration in the deflexion conld be perceived. The series of operations was repeated with the same result. It was estimated that an alteration of 5 per cent. could be detected.

In conclusion we must express our great indebtedness to Lord Kelvin and Dr. J. T. Bottomley for their interest and advice in the course of these experiments.

Blythswood Laboratory,

Renfrew, N.B.

LXXXIX. On the Application of Alternating Currents to the Calibration of Capacity-boxes, and to the Comparison of Capacities and Inductances. By W. Stroud, M.A., D.Sc., Cavendish Professor of Physics, and J. H. OATEs, B.Sc., Assistant-Demonstrator in the Physical Laboratory at the Yorkshire College, Leeds**

TN the May number of the Philosophical Magazine for the current year there appeared a paper by Prof. Fleming and $\mathrm{Mr}$. Clinton upon the measurement of small capacities and inductances. By means of a substantially built and rapidly revolving commutator and a special form of movable double-coil galvanometer, capacities amounting to only a few micro-microfarads and inductances amounting to only a few millibenries are measured. For some time prior to the publication of this paper we had been engaged upon the solution of a similar problem, viz. the accurate comparison of a capacity with either an inductance or a second capacity; we bad not, however, any idea of measuring such very small capacities as those dealt with by Prof. Fleming's method, neither had we any idea of the practical importance of such

* Communicated by the Authors. 


\section{Prof. Stroud and $\mathrm{Mr}$. Oates on the Application of}

measurements. Within the last few months, however, we have succeeded in increasing the sensitiveness of our apparatus to such an extent that we can detect a capacity of say one-third of a micro-microfarad, and we can measure with certainty a small inductance to at least two microhenries, $i . e$. one five-hundredth of a millihenry.

In connexion with this question of the detection of a capacity amounting to a fraction of a M.M.F. (1 M.M.F.= 1 micro-microfarad $=0.9$ electrostatic unit), it sbould be remembered that J. J. Thomson and Searle* and E. Rosa $†$ succeeded in detecting very small capacities in their respective determinations of " $v$." These experimenters were, however, using very sensitive high resistance galvanometers.

Our solution of the problem is in some respects simpler than that of Prof. Fleming. As to sensitiveness our apparatus is probably not quite so sensitive for the measurement of very small capacities, whereas for the measurement of small inductances it is, we think, superior. On the other hand, our apparatus is not so suituable, in its present form at all events, for effecting the accurate measurement of " $v$ "

The essential feature of our method consists in the employment of what is substantially an electrodynamometer with laminated iron cores, or it may be briefly described as a movable-coil D'Arsonval galvanometer, in which the permanent magnet is replaced by an electromagnet, with a laminated iron core, actuated by a 100-volt alternating current. The solid iron core inside the moving coil of the ordinary D'Arsonval is in our instrument also replaced by a laminated one.

Donle $\ddagger$ has used a Bellati-Giltay electrodynamometer for the measurement of specific inductive capacities in an entirely different way. The oscillating current from an inductioncoil (without iron core) was passed through a condenser (with adjustable plates) joined in series with the electrodynamometer and the deflexion was observed. On inserting a parallel slab of the dielectric between the plates and readjusting their positions this deflexion was approximately reproduced.

Our instrument is used just like an electrodynamometer when it is arranged for measuring the conductivity of electrolytes, $i$. $e$. the field-magnet is placed across the mains, and the highly insulated movable coil is used to replace the galvanometer in the bridge. We have found this piece of

* Phil. Trans. vol. clxxxi. A (1890).

$\ddagger$ Wied. Ann. xl. p. 307 (1890).

+ Phil. Mag. Oct. 1889. 
apparatus of great utility (1) where there is no difference in phase between the currents in the two arms of the bridge, and (2) where the phases of the current in the moving coil and of the magnetic field are far removed from quadrature.

It is very important in connexion with the use of this instrument that the ends of the movable coil should be permanently attached to the bridge - to use Wheatstone bridge terminology the key must be in the battery-circuit and not in the galvanometer circuit, in fact it is absolutely essential that there should be no key in the galvanometer circuit. The reason for this is as follows:-The "false-zero" position of the movable coil, i. e. the position it takes up when the alternating current is magnetizing the field, is a function of several things, (1) its zero position for no alternating field, (2) the intensity of the alternating field, (3) the shape, size, and conductivity of the metal frame on which the coil is wound, (4) the resistance and capacity in circuit as a shunt on the movable coil. Thus, for example, suppose the field is magnetized by an alternating current and that we join up the terminals of the movable coil to a resistance-box, we shall probably find that the "false-zero" position depends on the resistance; we shall certainly find that this is the case if we twist the head, which supports the strip carrying the coil, so that the latter is in an asymmetrical position in the field. If the coil be short-circuited we find that it takes up a position of great stability in what would be magnetically a symmetrical position were it not for the torsional effect of the strip; as it is, the position taken up is intermediate between its original zero position before the magnetization of the field and the position it would take up if there were no torsional rigidity in the strip. This being so it is clear that any increase in resistance in the short-circuiting box will have the effect of diminishing the deflexion due to the alternating field, and so the "false-zero" position of the coil is a function of the resistances when that coil is used as a galvanometer in an ordinary Wheatstone's bridge circuit. The apparent vagaries due to this "false-zero" bothered us a good deal at one time, although no doubt we ought to have foreseen all these points.

A number of experiments were made upon the positions of equilibrium of copper frames of various shapes and sizes when suspended in the alternating field, and although there is nothing new in any of these results (all of them being entirely in conformity with Elihu Thomson's experiments on the repulsion produced by alternating currents), yet it may be well to reproduce some of them so that if the instrument 
we are describing ever comes into use in physical laboratories its behaviour may be better understood. In describing these experiments we shall speak of a frame which sets itself so as to include the maximum or minimum number of lines of forces as being equatorially or axially stable respectively.

Experiment 1.-A thin copper wire (No. 24) with its ends joined so as to form a rectangle was axially very stable as we expected. The equatorial position was also one of stability, though to a much less extent.

Experiment 2.-A similar wire with the ends insulated from one another was equatorially stable to a small axtent, axially unstable.

Experiments 3 \& 4.-Precisely similar results were obtained with a thicker copper wire (No. 16) bent into a similar shape.

Experiment 5.-A rectangular frame was made out of a strip of thin sheet copper $16 \mathrm{cms}$. long and $2 \mathrm{cms}$. wide with the ends soldered together. This proved to be axially very unstable, equatorially very stable.

Experiment 6.-This frame hehaved in just the same manner when the ends were insulated from one another.

Experiment 7.-A D'Arsonval coil with the ends joined showed great axial stability (as of course was expected).

The explanation of the behaviour of the frames in these experiments is very simple. As is well known a coil of wire, with the ends joined, in an alternating field sets itself so that there is minimum magnetic induction through it, $i . e$. axially (Expt. 7). Continuous metal sheets in which the induced currents can freely circulate are vigorously repelled (Expts. $5 \& 6), i$.e . set equatorially. Thus it will be seen that the one effect or the other may predominate according to the shape of the frame.

When we originally devised the method here described, as it happened we had in our possession a D'Arsonval galvanometer with a field produced by an electromagnet. It was easy to try the method with this instrument (afterwards referred to as A) by simply substituting alternating for continuous currents in the coils surrounding the fieldmagnets. We were very well pleased with the results, especially considering the very feeble magnetization of the solid soft-iron core. We next had an instrument made with laminated iron cores. The electromagnet was built up of soft charcoal-iron stampings, $0.3 \mathrm{~mm}$. thick, in the shape of a hollow rectangle-one short side being missing- $21 \cdot 6 \mathrm{cms}$. long hy $8.9 \mathrm{cms}$. wide. The limbs were $2.5 \mathrm{cms}$. broad, and the stampings were first varnished and then piled up to a 
thickness of $2.5 \mathrm{cms}$. The lower part of each long limb was surrounded by a wooden frame $12.7 \mathrm{cms}$. long, on which were wound 370 turns of No. 20 copper wire. A brass cross-piece supported from the poles of the electromagnet carried an insulated torsion-head, from which was suspended the moving coil, which swung between the poles of the electromagnet.

We fully anticipated that the movable coil (especially if wound on a copper frame) would exhibit great axial stability, and consequently very little sensitiveness. To overcome this defect we originally tried supporting the coil by a crossed bifilar so as to partially neutralize the axial stability by superposing gravitational instability, but the result was far from successful. W $\theta$ then tried the effect of increasing the accuracy of reading without attempting to reduce the axial stability by attaching a pointer to the coil. Horizontal rigidity was imparted to the pointer by making it of a light aluminium wire $30 \mathrm{cms}$. long, bent in the middle at a very acute angle so as to form a $\mathrm{V}$. This was lightly latticed across the middle to increase the rigidity. The two free ends of the $\mathrm{V}$ were attached in a horizontal plane to the upper part of the coil, and the weight suitably counterpoised. The acute end of the $\mathrm{V}$, to which was attached a suitable mark, could be examined by a microscope, magnifying 16 diameters, placed with its axis horizontal, although we should have preferred a vertical arrangement of axis if that had been equally easy to attain. After considerable practice with this method of reading the position of a movable coil, we much prefer it for laboratory purposes to the ordinary mirror-and-scale arrangement. For rough work the pointer can be viewed directly in full daylight without the microscope, the latter only being used for the final adjustment of the balancing resistances. However, the necessity for using this method of indication has now disappeared, for we have by accident discovered a method of adjusting the sensitiveness with the utmost ease and convenience. If the moving coil is wrapped on a closed copper frame of appropriate breadth, this frame will possess axial instability in the alternating field (see expt. 5 above), whereas the movable coil, if short-circuited, would possess immense axial stability (see expt. 7); so that if we shunt the movable coil through a variable resistance, in all cases many times its own, we can get any degree of stability desired. We are thus in a position to employ the mirror method of reading the deflexions if we so desire. We are, however, ourselves convinced that the mirror method is a mistake in many cases where the movable system is heary 


\section{Prof. Stroud and Mr. Oates on the Application of}

or of a large size. We are, of course, aware of the evil effects of convection-currents upon such long pointers; in fact, in one form of movable coil (which we shall refer to as B), consisting of 211 turns of No. 38 copper wireresistance $=30$ ohms-wound on an aluminium rectangular frame $5 \cdot 5 \mathrm{cms} . \times 2 \cdot 5 \mathrm{cms}$. and $0.6 \mathrm{~cm}$. broad, these convectioncurrents proved a great nuisance. This effect, however, was almost entirely eliminated by surrounding the pointer by a fixed brass tube which had been flattened very considerably. The mark on the pointer only just protruded through the open end of this tube. In a later form of coil (referred to as C), consisting of 1508 turns of No. 42 copper wire-resistance $=485 \mathrm{ohms}$ - wound on a copper frame $5.5 \mathrm{cms} . \times 2.5 \mathrm{cms}$. and $2 \mathrm{cms}$. broad, we can observe very well without this protecting tube. However, in a final form of our instrument we hope to have the magnetizing coils entirely outside the case supporting the movable parts. It would, moreover, be desirable to have the torsion-head which supports the coil readily accessible firom the outside.

We shall consider (i.) the comparison of capacities of the order of from $10^{-3}$ to 1 microtarad ; (ii.) the comparison of capacities of the order of a few M.M.F.'s ; (iii.) the comparison of an inductance of the order of a henry with a capacity ; and (iv.) the measurement of an inductance of the order of a few microhenries.

Comparison of Capacities and Calibration of Capacity-lonx.The method we have used is the well-known one of De Sauty, the alternating current at 100 volts, from the Leeds

Fig. 1.

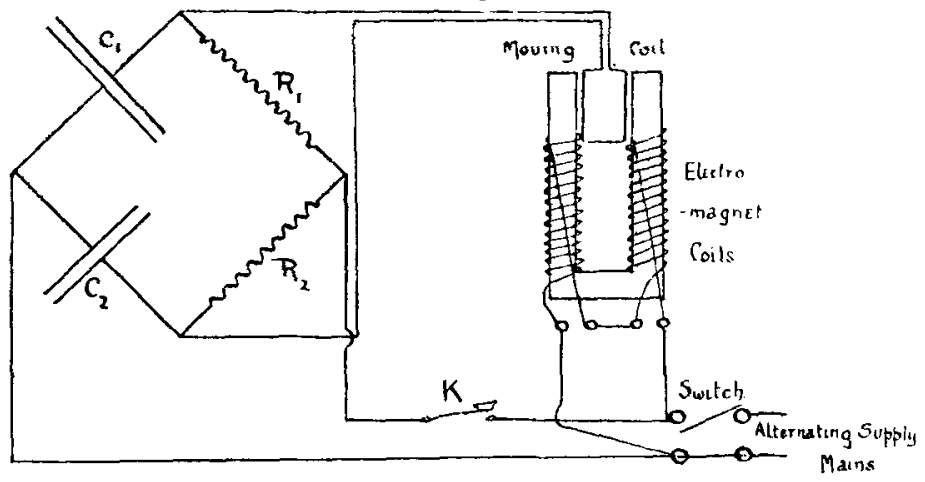

mains, being supplied to the bridge as shown in fig. 1 . It will be seen that as there is a capacity in each limb of the bridge, the only currents traversing the high resistances $R_{1}$ 
and $R_{2}$ are those required for charging the condensers ; the beating-effects of these currents are comparatively small, especially as the key, $K$, supplying the bridge is only momentarily depressed. The condition for a balance in De Sauty's method is that $\mathrm{C}_{1} \mathrm{R}_{1}=\mathrm{C}_{2} \mathrm{R}_{2}$. Now the tangents of the angle of the lag in the two limbs of the bridge are $\left(\mathrm{L}_{1} p-\frac{1}{\mathrm{C}_{1} p}\right) / \mathrm{R}_{1}$ and $\left(\mathrm{L}_{2} p-\frac{1}{\mathrm{C}_{2} p}\right) / \mathrm{R}_{2}$, and since $\mathrm{L}_{1}$ and $\mathrm{L}_{2}$ are both approximately zero, the lags become $\tan ^{-1}\left(-\frac{1}{\mathrm{C}_{1} \mathrm{R}_{1} p}\right)$ and $\tan ^{-1}\left(-\frac{1}{\mathrm{C}_{2} \mathrm{R}_{2} p}\right)$, so that when the condition $\mathrm{C}_{1} \mathrm{R}_{1}=\mathrm{C}_{2} \mathrm{R}_{2}$ is satisfied the lags are precisely the same.

We had in our possession a capacity-box, Elliott No. 65 , consisting of five capacities labelled $\cdot 5, \cdot 2 \mathrm{~A}, \cdot 2 \mathrm{~B}, \cdot 05 \mathrm{~A}$, and $.05 \mathrm{~B}$. These capacities could be divided at any junction into two groups, the two groups being in series and the members of each group being joined in parallel; they were also capable of being used singly or together. We took the capacity labelled 5 as having a true capacity of $0.5 \mathrm{MI.F}$., and compared each. of the other capacities and various combinations of them with it, and obtained the results given in the following table.

\section{TABLE I.}

Results obtained using Coil B. $\mathrm{C}_{1}=0.5 \mathrm{M} . \mathrm{F}$.

\begin{tabular}{|c|c|c|c|c|}
\hline Capacity tested. & $\mathbf{R}_{\mathrm{l}}$. & $\mathrm{R}_{2}$. & $\mathrm{C}_{2}=\mathrm{C}_{1} \cdot \frac{\mathrm{R}_{1}}{\mathrm{R}_{2}}$ & $\begin{array}{c}\text { Calculated } \\
\text { values of } \mathrm{C}_{2} \text {. }\end{array}$ \\
\hline $\begin{array}{c}.05 \mathrm{~B} \\
.05 \mathrm{~A} \\
.2 \mathrm{~B} \\
\cdot 2 \mathrm{~A} \\
.05 \mathrm{~B}+.05 \mathrm{~A} \\
.2 \mathrm{~B}+.05 \mathrm{~B} \\
.2 \mathrm{~B}+.05 \mathrm{~A} \\
.2 \mathrm{~A}+05 \mathrm{~B} \\
.2 \mathrm{~A}+.5 \mathrm{~A} \\
.2 \mathrm{~B}+05 \mathrm{~A}+.05 \mathrm{~B} \\
.2 \mathrm{~A}+.05 \mathrm{~A}+.05 \mathrm{~B} \\
.02 \mathrm{~A}+\cdot .2 \mathrm{~B} \\
2 \mathrm{~A}+\cdot 2 \mathrm{~B}+05 \mathrm{~A}+.05 \mathrm{~B}\end{array}$ & $\begin{array}{r}1970 \cdot 3^{*} \\
1970 \cdot 3 \\
985 \cdot 2 \\
985 \cdot 2 \\
1970 \cdot 3 \\
9852 \\
985 \cdot 2 \\
985.2 \\
985 \cdot 2 \\
1970 \cdot 3 \\
1970 \cdot 3 \\
1970 \cdot 3 \\
1970 \cdot 3\end{array}$ & $\begin{array}{c}19738 \\
19722 \\
2483 \cdot 6 \\
2492 \cdot 7 \\
9869 \cdot 6 \\
1984 \cdot 1 \\
1983 \cdot 9 \\
1989 \cdot 6 \\
1989 \cdot 1 \\
3304 \cdot 2 \\
3310 \cdot 9 \\
2487 \cdot 0 \\
1986 \cdot 2\end{array}$ & $\begin{array}{l}\cdot 049912 \\
\cdot 049952 \\
\cdot 19834 \\
\cdot 19762 \\
\cdot 09982 \\
\cdot 24827 \\
\cdot 24830 \\
\cdot 24750 \\
\cdot 24765 \\
\cdot 29816 \\
\cdot 29755 \\
\cdot 39613 \\
\cdot 49601\end{array}$ & $\begin{array}{c}\text { Assumed } \\
, " \\
" \\
\cdot 09986 \\
\cdot 24825 \\
\cdot 24829 \\
\cdot 24753 \\
\cdot 24757 \\
\cdot 29820 \\
\cdot 29748 \\
.39596 \\
.49582\end{array}$ \\
\hline
\end{tabular}

* The decimal points are due to the fact that we have been using a B.A. box. This box has been carefully calibrated, and the results expressed in legal ohms.

The sensitiveness of adjustment in these observations amounts to 5 M.M.F.'s, nevertheless we find that the ratio of two capacities obtained on different days is nothing like so consistent as the sensitiveness would lead us to infer that it 


\section{Prof. Stroud and Mr. Oates on the Application of}

should be. We have been driven to the conclusion that the ratio of certain pairs of our capacities is a function of the temperature. This may well be the case when we consider that the capacities are finally adjusted by squeezing. The result of a change in temperature may thus produce much greater effects due to stress in the case of one capacity than in that of another. This notion is confirmed by the following very rough experiments on the effect of change of temperature on the ratio of two capacities, the results of which are given in Table II. The experiments would have been done much more carefully if it had been possible to have measured the temperature of the condensers, but no provision had been made in the box for the insertion of a thermometer. We propose to investigate this point later.

TABLE II.

\begin{tabular}{|c|c|c|c|}
\hline Remarks. & $\mathrm{C}_{1}$. & $\mathrm{C}_{2}$. & $\mathbf{R}_{2}$. \\
\hline & 0.5 & $.05 \mathrm{~B}$ & 100374 \\
\hline $\begin{array}{l}\text { Left current on for five minutes and } \\
\text { tested. }\end{array}$ & $\ldots$ & ... & 100400 \\
\hline 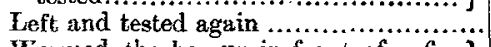 & $\ldots$ & ... & 100360 \\
\hline $\begin{array}{l}\text { Warned the box up in front of a fire } \\
\text { and tested again }\end{array}$ & $\ldots$ & $\ldots$ & 100370 \\
\hline Warmed again and tested & $\ldots$ & $\ldots$ & $10: 390$ \\
\hline$" \quad " \quad \quad \cdots \ldots . .$. & ... & $\ldots$ & 100420 \\
\hline (n............... & .. & $\cdots$ & 100450 \\
\hline 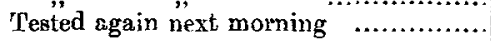 & $\ldots$ & $\ldots$ & 100394 \\
\hline
\end{tabular}

These results seem to show that the ratio of the two capacities compared decreases as the temperature rises. If it be true that the ratio of two capacities varies with temparature, it follows that a capacity must have quite a sensible temperature-coefficient.

We also had in our possession a Kelvin air-leyden made by $W$ hite and engraved as 0025 M.F. This we compared with the Elliott-box with the following results.

TABLE III.

\begin{tabular}{|c|c|c|c|c|}
\hline$C_{1}$ & $\mathrm{C}_{3}$. & $\mathbf{R}_{2}$ & $R_{1}$ & $\mathrm{C}_{1}=\mathrm{C}_{2} \cdot \frac{\mathrm{R}_{2}}{\mathbf{R}_{1}}$ M.F.'s. \\
\hline $\begin{array}{c}\text { The } \\
\text { Kelvin } \\
\text { air- } \\
\text { leyden. }\end{array}$ & $\begin{array}{c}\text { The } \\
\text { Elliott } \\
\text { Box } \\
\text { totalling } \\
\text { I M.F. }\end{array}$ & $\begin{array}{l}197 \cdot 05 \\
206 \cdot 90 \\
216 \cdot 74 \\
226 \cdot 58 \\
236 \cdot 42 \\
246 \cdot 27 \\
256 \cdot 11 \\
265 \cdot 95 \\
275 \cdot 80\end{array}$ & $\begin{array}{r}79703 \\
83689 \\
87660 \\
91681 \\
95654 \\
99595 \\
103624 \\
107625 \\
111636\end{array}$ & $\begin{array}{l}\cdot 0024722 \\
.0024723 \\
.0024725 \\
0024714 \\
.0024716 \\
.0024727 \\
.0024715 \\
.0024711 \\
.0024706\end{array}$ \\
\hline
\end{tabular}


An ordinary "quart" leyden-jar was compared with the air-leyden with the following results.

TABLE IV,

\begin{tabular}{|c|c|c|c|c|}
\hline $\mathrm{C}_{\mathbf{r}}$ & $\mathrm{C}_{2}$ & $\mathbf{R}_{2}$ & $R_{2}$ & $\mathrm{C}_{1}=\mathrm{C}_{2} \cdot \overline{\mathrm{R}}_{\mathrm{i}} \mathrm{M}$ M.F.'s. \\
\hline $\begin{array}{l}\text { A "Quart" } \\
\text { leyden-jar. }\end{array}$ & $\begin{array}{l}\text { The Kelvin } \\
\text { air-leyden } \\
={ }^{\frac{1}{\delta}} \delta \mathrm{M} \text { M.F. }\end{array}$ & 5030 & 9000 & .001119 M.F.'s. \\
\hline
\end{tabular}

It will thus be seen that two leyden-jars can be compared with an accuracy approaehing $\frac{1}{10}$ per cent.

By constructing an air-condenzer, preferably in the form of two concentric tubes, as recommended by Prof. Fleming, and comparing its capacity with that of a standard condenser, first with air as the dielectric, and secondly with another medium replacing the air in the condenser, it is possible to find the specific inductive capacity of that medium.

It will, we think, be admitted that the method of comparing capacities described is one of great convenience and accuracy. It is as easy to carry out as an ordinary Wheatstone's-bridge measurement of resistance, and now that alternating currents are so easily procurable, we hope that the method will be found useful in the workshop as well as in the laboratory.

Comparison of Small Capacities.-For capacities of the order of a few M.M.F.'s the Wheatstone's bridge is not so suitable. In this case it is preferable to join the capacity up in series with the moving coil, and to put the whole pressure on the coil. To get increased sensitiveness we constructed the coil $\mathrm{C}$, described above. A very rough air-condenser was made of two sheets of tin plate $10 \mathrm{cms}$. $\times 10$ cms., separated by three small pieces of ebonite $0.5 \mathrm{~cm}$. thick. The capacity of this is approximately $18 \cdot 8$ M.M.F.'s. The coil was deflected through in angle equivalent to $6^{\circ}$ after magnification in the microscope. The same tin plates separated by ebonite $1.3 \mathrm{~cm}$. thick (capacity $=7 \cdot 1$ M.M.F.'s) gave a deflexion equivalent to $2^{\circ} 4$. It was estimated that $\frac{1}{24}$ of this, $i$. e. 0.3 M.M.F., would have produced an observable effect. In this case the lag in the current expressed by $\tan ^{-1}\left(\mathrm{~L} p-\frac{1}{\mathrm{C} p}\right) / \mathrm{R}$, is almost exactly $-\pi / 2$, for though $\mathrm{L}$, the self-induction of the moving coil, is quite appreciable, yet its effect is completely drowned by the exceedingly large value of $\frac{1}{\mathrm{C}}$. 


\section{Prof. Stroud and Mr. Oates on the Application of}

Up to the present we have carried out only the roughest measurements of these very small capacities. For quantitative experiments we propose to construct a small aircondenser of variable capacity, so as to reproduce the deflexion.

Comparison of Capacities with Inductances of the Order of a few millihenries and upwards. - The arrangement we adopt is founded on that described by Prof. Anderson*.

On the publication of Prof. Anderson's paper one of us saw that the method could be improved by placing the high resistance " $r$ " $\dagger$ in the battery-circuit instead of in the galvanometer-circuit. This resistance " $r$ " is frequently of the order of 2000 or 3000 ohms; and when joined in series with an ordinary high-resistance D'Arsonval in the galvanometercircuit, it reduces its sensitiveness very considerably; whereas when placed as shown in fig. 2, the effect of its resistance can be annulled by increasing the potential of the battery, the currents in the arms of the bridge remaining the same as before. This modification of Anderson's method has been in use at the Yorkshire College for ten years. The relation between $\mathrm{L}$ and $\mathrm{C}$ may be proved to be

$$
\mathrm{L}=\mathrm{CP}\left\{\frac{r \cdot \mathrm{S}}{\mathrm{Q}}+\mathrm{S}+r\right\}
$$

The old method of working an experiment with a battery is as follows:-'The bridge is balanced for steady currents, then the galvanometer-key is closed and the battery-key is made or broken, whilst " $r$ " is adjusted till there is no induction-throw. The galvanometer we use is a $6600-0 \mathrm{hm}$ Elliott pattern astatic instrument. The pressure is about 17 volts, of which from 10 to 50 per cent. are applied to the terminals $d$ and $e$ of the bridge.

While getting the balance for steady currents it is convenient to join a carbon resistance-box in series with the inductance. This carbon rheostat consists of 20 or 30 pieces of ordinary battery-carbon which can be compressed by a screw. It is preferable to put this adjustable resistance in the arm $e g$ and not in the arm $e f$, as then no measurement of this carbon resistance is required. As the inductances are usually made of copper with a considerable temperaturecoefficient, it is continually necessary to verify the steady current-balance. If much difficulty is experienced in getting the steady balance, it is frequently well to bank up the arms $\mathbf{P}$ and $\mathbf{R}$ with non-inductive resistances.

* Phil. Mag. vol xxi. p. 329 (1891), or Electrician, vol. xxvii. p. 10.

+ Fleming and Clinton, Phil. Mag. Mity 1903, Plate I. 
Alternating Currents to Calibration of Capacity-boxes. $\quad 717$

The following results were obtained by this modification of Anderson's method for a copper coil which we have been using throughout these experiments.

TABLE V.

\begin{tabular}{|c|c|c|c|}
\hline & o. & $r$ & L. \\
\hline $\begin{array}{l}S=Q=1000 \text {, and } P=130 \\
\text { B.A. ohms, throughout. } \\
C \text { is the nominal value of the } \\
\text { capacity. } \\
\text { The value of } \mathrm{L} \text { is given cor- } \\
\text { rected for the true value of } \\
C \text { and for } S, Q, r \text {, and } P \\
\text { being in B.A. ohms. }\end{array}$ & $\begin{array}{c}1 \times 10^{-6} \text { farads } \\
2 \times 10^{-6} \\
-3 \times 10^{-6} \quad, \\
4 \times 10^{-6} \quad ", \\
5 \times 10^{-6} \quad ", \\
6 \times 10^{-6} \quad ", \\
7 \times 10^{-6} \quad ", \\
8 \times 10^{-6} \quad ", \\
9 \times 10^{-6} \quad ", \\
1.0 \times 10^{-6} \quad ",\end{array}$ & $\begin{array}{r}17000 \\
8300 \\
5340 \\
3900 \\
2960 \\
2400 \\
1990 \\
1680 \\
1440 \\
1240\end{array}$ & 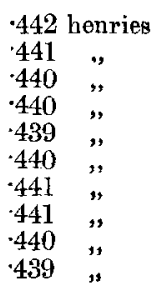 \\
\hline
\end{tabular}

The sensitiveness of adjustment is about 1 in 250 , or 4 per cent., in these experiments.

In what follows it is necessary to remember that we are no longer using a sensitive high-resistance galvanometer, but a moving coil instrument of from 30 to $500 \mathrm{ohms}$ ' resistance. On the other hand, we are using a much higher pressure, viz. 100 volts., of which from 10 to 50 per cent. is applied to the high-resistance coils forming the bridge. This pressure is only applied for a very small fraction of a second at a time during the act of testing. It is of course necessary at first to balance the bridge for direct currents as before, and for this purpose the magnetic field in the galvanometer must be generated by a direct current. Thus it is necessary to supply both direct and alternating currents to both the bridge and the field-magnet coils. Arrangements. were made as shown diagrammatically in fig. 2.

$\AA$ series of experiments were performed with instrument $\mathrm{A}$, the sensitiveness of adjustment being approximately 1 in 4000, or $\cdot 025$ per cent.

A second series of experiments were performed, using the coil $\mathrm{B}$ on the new instrument, the results of which are given below in Table VI. (p. 718). The sensitiveness here was about 1 in 8000 , or 012 per cent.

Measurement of very small Inductances.-The foregoing experiments show that it is possible to measure an inductance with certainty to something well under $\frac{1}{10}$ of a millihenry.

Phil. Mag. S. 6. Vol. 6. No. 36. Dec. 1903. 
TABLE VI.

\begin{tabular}{|c|c|c|c|c|}
\hline & Capacity. & $r$. & \multicolumn{2}{|c|}{ L, } \\
\hline $\begin{array}{l}\mathrm{S}=985 \cdot 2 \text { ohms. } \\
\mathrm{Q}=984 \cdot 7 \text { ohms and } \\
\mathrm{P}=130 \text { ohms. } \\
\text { All values of resist- } \\
\text { ances are given in } \\
\text { legal obms. } \\
\text { The capacity used } \\
\text { was the Elliott box } \\
\text { and the names of } \\
\text { the various plugs } \\
\text { are used to denote } \\
\text { the capacities. }\end{array}$ & 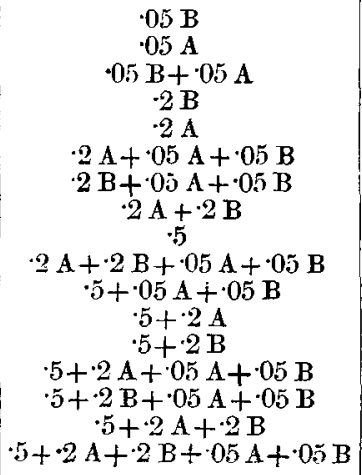 & \begin{tabular}{c|}
33678 \\
33648 \\
16563 \\
8066 \\
8091 \\
$5209 \cdot 0$ \\
$5197 \cdot 0$ \\
$3788 \cdot 5$ \\
$2911 \cdot 8$ \\
$2930 \cdot 0$ \\
$2337 \cdot 0$ \\
$1941 \cdot 1$ \\
$1938 \cdot 6$ \\
$1635 \cdot 9$ \\
$1634 \cdot 1$ \\
$1400 \cdot 6$ \\
$1211 \cdot 2$
\end{tabular} & $\begin{array}{l}\cdot 44355 \\
.44354 \\
.44275 \\
.44146 \\
.44113 \\
\cdot 44116 \\
\cdot 44118 \\
\cdot 44101 \\
44266 \\
.44137 \\
\cdot 44146 \\
\cdot 44157 \\
.44154 \\
.44152 \\
\cdot 44149 \\
\cdot 44125 \\
\cdot 44139\end{array}$ & 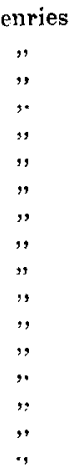 \\
\hline
\end{tabular}

We therefore decided to see what could be done in the way of measuring a very small inductance indeed. We took a coil of copper wire, having 4 layers of 80 turns each, the resistance being $0.2 \mathrm{ohm}$. The length of the coil was $16.6 \mathrm{cms}$. and the mean diameter $2.1 \mathrm{cms}$. We can roughly calculate a superior value for the inductance of this, by assuming the field uniform and neglecting the effect of the ends. We have $\mathrm{L}=4 \pi \mathrm{N}^{2} A / l$, where $\mathrm{N}$ represents the total number of turns, $l$ the length of the coil, and A the equivalent area. $\mathrm{N}$ and $l$ could be accurately obtained, but $\mathrm{A}$ may easily have been \pm 10 per cent. wrong. Substituting in the above formula we obtain $\mathrm{L} \fallingdotseq 268$ microhenries.

This inductance was measured as described above, but with this modification, which is, we think, an improvement when the greatest possible accuracy is desired. A balance was obtained with steady currents on a sensitive bridge by varying a high resistance $S$ used as a shunt to the coil $C$. A piece of copper wire $\mathrm{W}$ of the same cross-section as $\mathrm{C}$ and of slightly longer length was taken, and by means of a rock-over switch could be readily substituted for $C$. The length of $W$, about 30 feet, was then carefully adjusted until it produced precisely the same (almost zero) effect as $\mathrm{C}$ itself. This length was then (while still connected to the switch) wound non-inductively and then placed in contact with the coil. The shunt $S$ was now removed and the rock-over switch together with $C$ and $W$ were transferred to the inductance-bridge and placed 
Altemating Currents to Calibration of Capacity-boxes. $\quad 719$ in the arm $R$ (see fig. 2). We are now in a position to dispense altogether with the stendy currents in the inductance

Fig. 2.

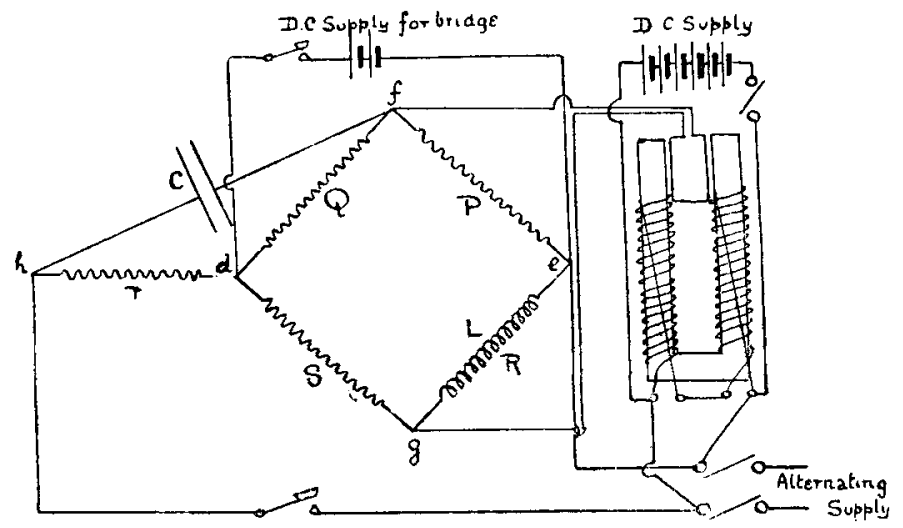

measurement. The bridge is balanced with $W$ and 30 or 40 ohms non-inductive resistance in the arm, but without the condenser connected to the bridge. The switch is then rocked over, the condenser connected, and the bridge again balanced for $\mathrm{C}$ by adjusting the resistance $r$. We found the experiment hopeless with the air-leyden, $r=0$ and $r=\infty$ giving deflexions in the same direction. Obviously the capacity of the air-leyden was too great. We therefore constructed a rough air-condenser of two concentric tubes $34.4 \mathrm{cms}$. long, the mean diameter being $6.3 \mathrm{cms}$. The tubes were separated from one another by three small pieces of ebonite attached at each end to the inner tube. The calculated capacity of this condenser was 219 M.M.F.'s. On replacing the air-leyden by this condenser we could easily measure the inductance, and the following results were obtained using the moving coil C.

Table VII.

\begin{tabular}{|c|c|c|c|c|c|}
\hline c. & S. & Q. & $\mathbf{P}$. & $r$. & L. \\
\hline \multirow{3}{*}{219 M.M.F.'s } & 199 & $1869 \cdot 3$ & $4165 \cdot 5$ & $240 \cdot 7$ & 000241 henries \\
\hline & $19 \cdot 9$ & $984 \cdot 7$ & $2112 \cdot 7$ & $496 \cdot 8$ & $\cdot 000244$ \\
\hline & $19 \cdot 9$ & $1181 \cdot 7$ & $2526 \cdot 5$ & 415.2 & $\cdot 000245$ \\
\hline
\end{tabular}

3 B 2 
These results are in agreement with the admittedly rough calculation of the inductance from the dimensions of the coil. The sensitiveness was such that two microhenries could be detected with certainty.

By thus comparing a standard air-condenser with an inductance whose dimensions are sufficiently large and accurately measurable, we believe that " $v$ " could be determined with considerable accuracy.

We can also use a slight modification of the method described for the measurement of coefficients of mutual induction. The results obtained by the method we hope to publish shortly.

We had hoped that the method would have been applicable to the accurate determination of electrolytic conductivities; but though we can get consistent results up to $\frac{7}{10}$ per cent., anything much beyond that seems at present hopeless owing to the apparently erratic motion of the coil. The fact is, we presume, that the capacity of the electrodes is not constant, and the apparatus being so good for measuring capacities becomes correspondingly inefficient for resistances involving variable capacities. This explanation is confirmed by reducing the area of the electrodes; but even with electrodes of only $.02 \mathrm{~cm} .^{2}$ area or so, the results are only two or three times as consistent. Even with a balancing-cell * the results are not much better. Possibly, however, by making the ohmic resistance of the electrolyte used a negligible quantity the capacity of the electrodes might be measured instead.

Conclusion.-The apparatus and methods described will, we think, prove very useful for the calibration and adjustment of large and small capacities, and for the measurement of self-induction.

The Yorkshire College, Leeds. Sept. 28th, 1903.

XC. The Kinetic Theory of Gases.

To the Editors of the Philosophical Magazine. Gentlemen,

MR. BURBURY'S note on my "Kinetic Theory of 1 Gases developed from a new standpoint" seems to call for a reply, although his criticisms are so numerous and far reaching that I cannot ask for space in which to attempt to answer them at all fully.

* Phil. Mag. Jan. 1897. 